\title{
Gifted and talented children: Heterogeneity and individual differences
}

\author{
María Pereira Da Costa* and Todd I. Lubart
}

Paris Descartes University (Francia).

\begin{abstract}
Título: Niños superdotados y Talentos: Heterogeneidad y diferencias individuales.

Resumen: Superdotación es un tema amplio, que cubre muchos ámbitos de actividad y diversas manifestaciones. En este artículo examinamos dos temas específicos: (a) lo perfiles cognitivos de los niños superdotados, (b) el desarrollo del talento musical. El punto común de estos estudios es la observación de la heterogeneidad de los perfiles individuales. Los resultados del primer estudio realizado sobre 99 niños con un CI igual o superior de 130, muestra una amplia heterogeneidad en el potencial intelectual, el cual está enmascarado si observamos sólo el CI global. Un análisis de cluster jerárquico identifica seis clases de niños con perfiles medios contrastados. El segundo estudio es una investigación exploratoria, enla que intentamos describir el entorno de los estudiantes de música y evaluar la importancia que los padres y profesores dan a los principales factores de éxito en el entrenamiento musical. Nuestros resultados resaltan diversos perfiles diferenciales relacionados con los contextos de entrenamiento, centrados en la representación que los niños tiene sobre la música.

Palabras clave: Superdotados, talento musical, perfiles individuales, heterogeneidad.
\end{abstract}

\section{Introduction}

France has a long history concerning giftedness and its measurement. In the early $20^{\text {th }}$ century, Binet was commissioned by the French authorities to understand why some children succeed at school whereas others fail. The main idea was to identify and help children with difficulties at school, unable to study in regular classes. Binet and Simon's work led to the Metric Scale of Intelligence, based on the concept of mental age, the precursor of IQ (Binet \& Simon, 1905; 1908). When conducting his research, Binet noted that some children performed very well showing precocity and high abilities. At the time, Binet focused on academic abilities, because his main objective was to help children to succeed at school (Pereira Da Costa et al., 2013).

A few decades later, researchers such as Terman (1925) showed a great interest in children with high abilities. The identification of gifted children was a major issue, but other research issues became also very popular. In differential psychology, we are naturally interested in investigating individual differences related to giftedness and especially the heterogeneity of skills in gifted children. Looking only at an overall score such as IQ, and disregarding individual patterns, we do not correctly describe children with high analytical potential. The work, presented in the first part of this article, attempts to offer some insights into the ability profiles of gifted children and to help understand their specificities.

Research on high potential does not only concern analytical intelligence, although the psychometric approach to

* Dirección para correspondencia [Correspondence address]: María Pereira Da Costa. Paris Descartes University, Sorbonne Paris Cité, Institute of Psychology, Laboratory LATI, 71 avenue Vaillant, 92100 Boulogne-Billancourt (France). E-mail: maria.pereira@parisdescartes.fr
Abstract: Giftedness is a large topic, covering many domains of activity and diverse manifestations. In this paper, we examine two specific topics: (a) cognitive profiles of gifted children and, (b) musical talent development. The common point of these studies is the observation of the heterogeneity of individual profiles. The results of the first study performed on 99 children with an IQ equal to or higher than 130, shows a large heterogeneity in intellectual potential, which is masked if we look only on the overall IQ. A hierarchical clustering analysis identifies six classes of children with contrasting means profiles. The second study is an exploratory research, in which we try to describe the environment of music pupils and to evaluate the importance that parents and teachers give to the main success factors for musical training. Our results highlight several differentiated profiles relating to the contexts of training, centred on the representation that the child has of music.

Key word: Gifted, musical talent, individual profiles, heterogeneity.

identification with the Wechsler Intelligence Scales for Children (Wechsler, 2005) is often privileged and the definition of giftedness often limited to a high IQ score (Pereira Da Costa, 2010; Heller, 2004). Theoretical models proposed in the literature reflect an evolution of the concept of high potential. For example, Gagné's (2000, 2004) model is based on a clear distinction between two concepts: "gift" which designates the spontaneous expression of superior skills in four different areas: intellectual, creative, socio-affective and sensorimotor and "talent" which means the development of skills, superior knowledge and high level of performance in at least one of the areas designated by the model (academic, artistic, social, etc.). Research has often investigated the factors that contribute to the development of talent in a certain area of endeavor. In Gardner's (1983) Multiple Intelligences Theory, there are several areas of intellectual activity-- logico-mathematic, visuo-spatial, verbal, kinesthetic, interpersonal and intrapersonal, and musical. The work that we present in the second part of this article illustrates research on a specific ability domain. The domain chosen is music and the research findings indicate again that gifted children are a heterogeneous group, even within this specific domain of endeavor (Lubart \& Jouffray, 2006; Lubart et al., 2006; Pereira-Fradin, 2006).

\section{A. Analytic abilities and individual profiles}

In the process of identification of high potential, assessment of children's cognitive abilities has two objectives. The first is to place the child's level relative to a single specific criteria such as IQ; the second is to identify the strengths and weaknesses of the child and provide a differentiated profile. This second approach provides a better understanding of cogni- 
tive abilities and the possibility to tailor advice on education or remediation. In fact, regardless of the approach taken, the implicit assumption made is that the measured level of performance is related to a learning potential (Lautrey, 2002). The latest version of the Wechsler Intelligence Scales for Children (WISC-IV; Wechsler, 2005) assesses four factorial index scores striving to improve the psychometric identification of high potential; but is "high potential" a single entity?

\section{Inter and intra individual variability}

A key result in research on the measurement of potential in gifted children is the observation of large inter-individual variability. Studies indicate that gifted children are not a homogenous group, even if we restrict the potential to the field of analytical intelligence measured by classic intelligence tests like the Wechsler scales. The analysis of the results shows patterns with very large differences between children whose final scores are high, in the top $2.3 \%$ of their age group. We observed this ourselves in a study of the variability of individual profiles based on WISC-IV scores (PereiraFradin, Caroff, \&Jacquet. 2010).

This study was performed on 99 children with an IQ equal to or higher than 130, measured with a WISC-IV, aged 6-16years (mean age $=9$ years and 5 months). There were more gifted boys $(N=65)$ than girls $(N=34)$, as always in French studies (Brasseur \& Grégoire, 2010 ; Courtinat \& De Leonardis, 2010). This sex imbalance can be explained by the fact that teachers and parents focused more on boy's difficulties at school or behavioral troubles than on girls'. The imbalance observed in actual cases does not indicate differences in intelligence between boys and girls, examining data on children randomly selected according to the quota method shows that there are as many boys as girls with a IQ of 130 or more (Wechsler, 2005).

\section{Typical Profile}

In Figure1, we can see that gifted children have a typical level of performance on the Verbal Comprehension Index, which places them in the "Superior" (equal or above120) or "very high" (equal or above130) category compared to the mainstream population. On average, the results are slightly lower for the Perceptual Reasoning and Working Memory scores. The Processing Speed index is almost normal. The difference between the four indices is significant; $F(3,294)$ $=87.4, p<.05$. If we pursue this analysis at the individual level, we find that some children obtain "average" results (index scores between 90 and 110) for the last three indices presented in Figure 1; these children score below the generally accepted threshold for identifying high potential. In general, the results of the group of girls are no different from that of boys (Figure 1). Average patterns of results of these two groups are identical to that of the full sample.

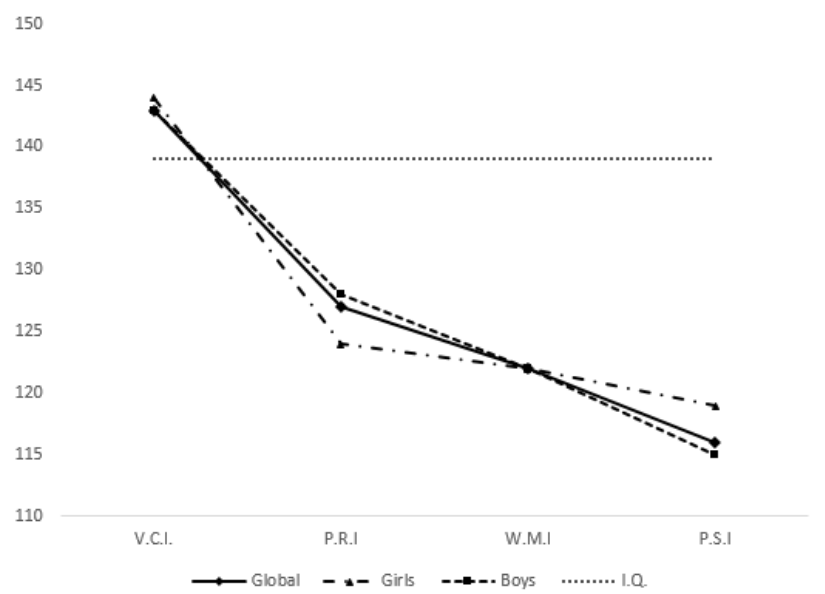

Figure 1. Patterns of IQ Index Scores (Verbal Comprehension, Perceptual

Reasoning, Working Memory, Processing Speed) according to gender.

Actually, if we focus on the analysis of these average profiles, we may not notice the heterogeneity of individual profiles on the four index scores measured by the WISC-IV. There are a large number of publications based on earlier WISC versions. An initial study by Silver and Clampit (1990) using the WISC-R collected on a representative sample of 2,200 children in the US shows a significant gap between Verbal IQ and Non Verbal IQ (both subscores were used to calculate IQ in this version of WISC). This difference was much more common in children with high intellectual potential than in the general population. Silver and Clampit used the standard 21-point difference between the two IQ subscores, which corresponds to a statistically significant difference. On this basis, the test manual data indicated that this difference was observed for $5 \%$ of the general population. But the frequency of differences at or above 21 points was $20 \%$ for children whose total IQ was 130 and $25 \%$ for children whose IQ was over 140.

Our study shows also that intra-individual variability is much higher in children with high intellectual potential than in the mainstream population. The WISC-IV (Wechsler, 2005, p. 91) follows Sattler's suggestion (2001) considering that unusual differences between scores would be observed in less than $10-15 \%$ of the normative sample. By reference to the WISC-IV Technical Manual (Table B.2), we analyzed individual profiles for children with IQ greater than or equal to 120 (Wechsler, 2005, p. 262)..This analysis shows that only 17 participants $(17 \%)$ had a homogeneous profile, without any unusual difference between their index scores. In contrast, 32 participants had 3 unusual differences between index scores, and one participant showed a difference for 6 index scores combinations. In conclusion, we can say that heterogeneous profiles $(83 \%)$ seem to be the norm in this sample of 99 gifted children. 


\section{Classification of individual profiles}

To create individual profiles, the four index scores from the WISC were analyzed using a hierarchical clustering tech- nique (aggregation by Ward's method). The analysis of aggregation distances identifies six classes of children with contrasting means profiles.

Table 1. Descriptive statistics for six groups of children from the classification (Number of participants, average scores and extent of scores)

\begin{tabular}{|c|c|c|c|c|c|c|}
\hline & $\mathrm{N}$ & I.Q. & V.C.I. & P.R.I. & W.M.I. & P.S.I. \\
\hline Group 1 & 23 & $\begin{array}{c}134 \\
{[130-142]}\end{array}$ & $\begin{array}{c}130 \\
{[120-143]}\end{array}$ & $\begin{array}{c}127 \\
{[111-146]}\end{array}$ & $\begin{array}{c}122 \\
{[115-138]}\end{array}$ & $\begin{array}{c}117 \\
{[106-134]}\end{array}$ \\
\hline Group 2 & 14 & $\begin{array}{c}146 \\
{[134-153]}\end{array}$ & $\begin{array}{c}139 \\
{[118-155]}\end{array}$ & $\begin{array}{c}130 \\
{[106-154]}\end{array}$ & $\begin{array}{c}127 \\
{[100-148]}\end{array}$ & $\begin{array}{c}139 \\
{[115-150]}\end{array}$ \\
\hline Group 3 & 10 & $\begin{array}{c}137 \\
{[130-142]}\end{array}$ & $\begin{array}{c}148 \\
{[143-155]}\end{array}$ & $\begin{array}{c}109 \\
{[104-116]}\end{array}$ & $\begin{array}{c}119 \\
{[109-130]}\end{array}$ & $\begin{array}{c}127 \\
{[118-137]}\end{array}$ \\
\hline Group 4 & 15 & $\begin{array}{c}148 \\
{[143-151]}\end{array}$ & $\begin{array}{c}152 \\
{[146-155]}\end{array}$ & $\begin{array}{c}135 \\
{[121-152]}\end{array}$ & $\begin{array}{c}128 \\
{[115-140]}\end{array}$ & $\begin{array}{c}119 \\
{[103-127]}\end{array}$ \\
\hline Group 5 & 17 & $\begin{array}{c}137 \\
{[130-146]}\end{array}$ & $\begin{array}{c}149 \\
{[135-155]}\end{array}$ & $\begin{array}{c}128 \\
{[116-135]}\end{array}$ & $\begin{array}{c}109 \\
{[97-115]}\end{array}$ & $\begin{array}{c}110 \\
{[96-124]}\end{array}$ \\
\hline Group 6 & 20 & $\begin{array}{c}137 \\
{[130-148]}\end{array}$ & $\begin{array}{c}148 \\
{[130-155]}\end{array}$ & $\begin{array}{c}126 \\
{[109-146]}\end{array}$ & $\begin{array}{c}126 \\
{[115-150]}\end{array}$ & $\begin{array}{c}97 \\
{[83-109]}\end{array}$ \\
\hline
\end{tabular}

The first subgroup corresponds to children whose profile is relatively homogeneous, their values are located within the 120-130 point range. Sub-groups 2 and 4 are characterized by an average IQ higher than 140 . For group 2, there is evidence that all the index scores are very close to 130 . For group 4 only the processing speed index score is below this threshold, but remains at a level "higher" than the mainstream population. In the last three sub-groups, the Verbal Comprehension index is the same level as the global IQ. However, the values of some index scores are significantly lower than the generally accepted threshold for the identification of giftedness and correspond to a "medium-level". These are the Perceptual Reasoning index score for group 3, the "medium-level" Working Memory and "medium-level" Processing Speed index scores for group 5 and the Processing Speed Index score for group 6.

\section{Conclusion}

By observing the results of hierarchical clustering, we note that only group 2 has a very homogenous profile, which represents $14 \%$ of our sample. The other groups have at least one score which is below the standard 130 cut-off for giftedness. We observe a heterogeneity in intellectual potential, which is masked if we look only on the overall IQ.

Examining the patterns of IQ and index scores in detail, we see that the common point of these six profiles is the highest score for verbal comprehension (VCI) and perceptual reasoning (PRI) index scores. Success is less systematic for the working memory index score (WMI) and for the processing speed index score (PSI). These results are comparable to those observed in other studies. However, focusing on average profiles (Figure 1), one could believe that all gifted children had higher average scores for all the index scores, even if they are brighter in verbal tests and measures of factor $\mathrm{g}$. These observations lead some psychologists to use a General Ability Index (GAI) as an alternative to the measure of the academic intelligence (Saklofske et al., 2006 ; Weiss et al.,2006). The GAI is obtained in the WISC by adding the Verbal Comprehension and Perceptual Reasoning index scores. This measure minimizes the impact of the two other index scores and reduces the heterogeneity of profiles observed. The main finding to be retained is that heterogeneity within the cognitive abilities of high potential children is common. This result is also compatible with the proposal that giftedness, when transformed into talent, is most often expressed in one domain (such as verbal, mathematics, or the arts).

\section{B. Beyond classical academic ability: The ex- ample of musical talent}

Some of our studies led us to take an interest in other capacities beyond analytical intelligence abilities as measured in intelligence tests. In the US, the Marland Report (1972) distinguished general intellectual abilities and academic skills and also expanded the inclusion of giftedness and talent to include leadership, creativity, arts and psychomotor skills. One artistic area in which high potential is expressed is music. In this domain, which we will consider here as an example, we can examine the expression of precocity, gifts, talent and individual differences in career success. We can study many characteristics of high potential by looking at the development of musical talent. Heterogeneity is again an important feature to take into consideration.

\section{Definition of musical talent}

Before presenting an empirical study on the identification of musical talent, we provide a definition of what is termed "musical ability" or "musical intelligence". Gardner (1983) indicates that children with musical intelligence are characterised by artistic interest, perseverance, high motivation and quick learning and also a high level of kinesthetic 
intelligence. According to Haroutounian (2000), a musically talented student shows creative interpretation: he/she enjoys extending, manipulating and experimenting with sounds, is eager to express ideas through music and spontaneously sings and moves to music. This gifted person shows also physical and technical ability in music based on prior training, and displays creative and expressive involvement in music. Motivational level is very high and gifted individuals can concentrate for extended periods of time during music practice, with persistence and perseverance in musical tasks. Enjoying working independently in music is another important characteristic. For Haroutounian, musical talent cannot be measured only by musical tests focused on elementary abilities such as pitch sense or rhythmic memory. It is necessary to include other dimensions measured by biographical and family information. Winner et Martino (2000) argue that if technical expertise can be developed and acquired by training, musical talent implies an innate sensitivity to musical emotions.

Two developmental theories can be applied to musical talent: Renzulli's "three-ring theory" (1986) and Gagné's model (2000). According to Renzulli's model, musical talent would be defined by above average performance in the musical domain, a very strong involvement in training and a high level of musical creativity. In his Differenciated Model of Giftedness and Talent, Gagné defines talent as the product of catalysts that enhance or impede natural abilities. Of course, in a specific domain as music, we can see very well how intrapersonal factors such as physical characteristics, concentration, and persistence, or environmental factors such as parent's interest in music can interact and have positive or negative impact on music learning and on the developmental processes involved in musical talent.

The Differentiated Model of Giftedness and Talent (DMGT) highlights the importance of environment and personality (motivation, perseverance, ability to learn from mistakes) in the development of talent (Gagné, 2010). Music is a domain in which we observe that some gifted children never express their musical talent, whereas others who appeared less gifted become professionals. The environment of the child and his/her personality give us some explanations underlying this heterogeneity.

For example, studies have highlighted the importance of the first music teacher, finding that many students said they had been encouraged by a friendly and attentive teacher at the beginning of their formation, thus suggesting that a first positive experience could have a profound impact on motivation to continue in the musical domain; Sosniak (1985) emphasized the importance of the relationship between the musician and his or her first teacher, students often prefer a warm and stimulating teacher compared to a very brilliant teacher. Another important environmental factor is the parents' attitude as they are often at the origin of the child's involvement in learning music. For example, Sloboda and Howe (1991) showed in a very selective school of music that $60 \%$ of students had started learning music at the instigation of parents or teachers rather than following a personal desire to learn music.

In the history of music we can find many examples of famous musicians who come from families of musicians. The best known example is Wolfgang Amadeus Mozart. His father was a great musician and his sister was a talented composer and musician (although her talent was eclipsed by the fame and the talent of her little brother); Mozart grew up in a rich and stimulating musical environment. The omnipresence of his father, who decided to make this child a prodigious musician, has also many consequences on the development of natural abilities noticed in young Wolfgang. The environmental context of a young musician in terms of cultural openness and motivational support seems to have a strong influence on the commitment to music education as well as on the persistence of individuals in his or her vocational choice. The expression of outstanding potential often requires hard work. Motivation is therefore essential to continue training despite failures. We can also remark the influence of the age of beginning musical training on the future specializations of musicians. Manturzewska (1990) noted that, proportionally, musicians starting relatively late when learning were oriented more towards composition or conducting.

Successfully learning music depends also on personality traits. Studies such as Alter's (1989) research have focused on the personality profile of young musicians considered gifted. The results showed that these talented musicians were more creative, energetic, independent and dynamic than others. Similarly, Freeman (2000) and Subotnik et al. (2003) found that self-confidence was one of the predominant characteristics of these individuals. As described, this apparent confidence is closer to a real charismatic confidence. According to Subotnik, charisma is essential for the expression of talent and is often synonymous with professionalism.

\section{Factors for success in musical training}

In the literature, exceptional success in the field of music is often evoked to illustrate examples of gifted children or prodigious young musicians. Sometimes confusion between the two terms is observed. The term "prodigy" designates a child who is able to play very early one or more instruments, who takes part quickly in concerts but who, at adulthood, will not be distinguished from other talented musicians who will have reached the same level of expertise. A prodigious child does not necessarily have an exceptional potential and a developed creativity, but simply a very great precocity which enables him or her to acquire technical skills at an astonishing level if we refer to chronological age norms (Winner \& Martino, 2000). Nevertheless, some of these children will combine precocity, high abilities and creative capacities. This combination leads them to be considered as geniuses. In music, the example of Mozart is very well- 
known, even if other musicians could be cited such as Bach, Beethoven, Saint-Saëns or Liszt.

Individual differences appear during the first stages of training. Of course, they may concern speed of acquisition concerning musical theory, instrumental expertise or technical skills. Differences between children can also be noted in motivational aspects such as perseverance or selfefficiency. Understanding what differentiates these children is particularly important within the framework of the study of exceptionally gifted children. Main individual differences on technical skills can be identified very well by teachers. It is more difficult to identify sources of differences that explain why some children who, at the beginning, seem to have the same potential will gradually show differences in music learning skills and later differences in professional success. How many teachers or parents evoke the case of "gifted" children who at the end will give up their formation whereas others who would never have believed it possible to achieve such a level, do indeed become exceptional? In French music academies, the attrition rate is very high; a synthesis published in 2003 (Brouet, 2003) indicates that $52,2 \%$ of the pupils leave music schools between the 1 st and the 2 nd cycle of musical formation. Understanding the reasons for this high rate of attrition is necessary in order to examine further the factors related to heterogeneity in musical talent development. There is currently no consensus on the origin of individual differences in talent. The interactionist theory seems to be the most promising approach. From this point of view, natural abilities can only be developed if a suitable environment allows them to be developed (Gagné, 2000; Freeman, 2000).

In this context, motivation to succeed plays a major role. The student must understand that he or she has a certain control over life events. This variable often makes the difference between a gifted child who has no self-confidence and a less gifted child who is sure of succeeding. Motivation involves two factors: an interest in music and perseverance. It is important to note that, in many cases, these factors are considered more relevant than the technical skills for the selection of exceptionally gifted children wishing to integrate specialized programs of musical formation. Several longitudinal studies show that for the beginners, an exceptional potential can be identified through the speed of progress. Thereafter, the best predictor of success will be the provided by quantity of work the children is able to furnish.

According to Subotnik (2000), these characteristics go hand in hand with adaptation to a highly competitive environment in which insensitivity to frustration and criticism is necessary in order to be handle rejection, at the same time helping the child to analyse the reasons for failure and also helping him or her to improve. Basing her conclusions on studies carried out at the Juilliard School in New York, Subotnik showed that social competency factors play also a determining role. The obligation to face an audience favours children who can cope with the stress associated with these situations; in other words, children who have good self- control can remain calm and have a remarkable ability to concentrate. She underlines also the fact that some of the greatest artists she observed showed a dominating will, expressed in messages through their interpretations or compositions. However, in order to "dominate" the audience, a musician must be very receptive to the reactions and needs of the public and for this reason social intelligence is involved.

During these last twenty-five years, the concept of social intelligence has been developed in several psychological theories (Coleman \& Cross, 2000). To define it precisely, we can refer to Gardner's multiple intelligences theory even if Gardner uses the terms "interpersonal intelligence" to refer to this concept. Within the framework, social intelligence refers to the aptitude to understand others through expressed thoughts or feelings, in a verbal and non-verbal way and to work out effective behaviors in situations of social interaction. This definition corresponds well to Subotnik's determinant in the professional success of exceptional musicians. These observations relate also to Sternberg's triarchic theory and the acquisition of tacit knowledge which characterizes practical intelligence (Sternberg, 1985).

If the individual characteristics that we have just evoked are judged as key factors in the development of musical talent, psychologists consider that a child's environment can facilitate or disturb their expression. The learning environment is made up of two major components: family and teachers. The family may contribute to musical talent development through the expression of three variables: socioeconomic status, a musical environment and family support. The contribution of socioeconomic status is obviously expressed in financial aspects. Not all parents have the financial means to pay for music classes, to purchase or rent instruments or to buy concert tickets on a regular basis. The effect of the musical environment has been underlined in many studies.

Some authors did not resist the temptation of a dangerous intellectual short cut and proposed that musical gifts have a genetic origin because one finds more children exceptionally gifted in music in families of high level musicians than in other families. For example at the end of the 19th century, Galton based his assertions on biographical studies such as the case of Johann Sebastian Bach family's whose several descendants became recognized musicians. Instead, we must not forget that being the son or the daughter of a musician means usually growing up in an environment where listening of the music and the interest for this art are very developed. In a scientific way, it was shown that the early exposure of children to music familiarized them with the perception of rhythm, melodies or tonal colors and facilitated later training. Consequently, the parents who love music contribute to the musical success of their children as much as the parents who are good musicians (Sosniak, 1990; Howe \& Davidson, 2003).

The attitude of the parents towards the motivation of their child is regarded as one of the most important devel- 
opmental sources for musical talent (Sloboda \& Howe, 1991). Freeman (2000) stresses that without an encouraging home environment, the exceptionally gifted children often give up their musical practice. Through case studies, she explains why, even if they had a major interest in music, many of these children need to be pushed to work and to be encouraged to succeed.

The impact of music professors appears on two levels: the first level is related to the nature and the quality of the relation between the master and the pupil; the second is related to the adequacy between the style of teaching and the child's own needs. Asking the young gifted children to define the perfect professor of music, the most frequent answers describe a cordial and friendly personality (Sloboda \& Howe, 1991). At the beginning of the training, many children move to another teacher because they find their first teacher too severe and unfriendly. We know also that the teacher-pupil relationship is so important that it can determine the choice of whether or not to pursue a professional career (Subotnik, 2000). From studies carried out on groups of children of different ages, Subotnik finds that at the beginning of musical training, the quality of this relationship is a more important factor for the development of the child's talent than the teacher's technical skills. However, when the gifted child reaches a certain level of training, the opposite is observed. From the analysis of interviews of teachers at the Juilliard School, Subotnik distinguished two independent and complementary components in teaching contents. The first relates to more or less obvious aspects of music training, such as technique, interpretation (although this is often neglected in training) and the presentation of the piece to be learned. The second component is more surprising, as it relates to a range of tacit knowledge essential for the success of a professional career. This component involves nonverbal communication, for example the choice of attire for public performances, the most appropriate behaviour on stage, stress management or even the knowledge of easy ways to cover up errors. This tacit knowledge is often transmitted in an abstract way and often explains why, also in the case of gifted children, some succeed and others fail (Sternberg, 1985). However, not all the teachers, or institutions, insist on these competencies, still considered as secondary or related to the child's musical "instinct".

\section{Description of musical training in France}

In order to understand better the results of our studies, it is important to describe musical training in France. At first, we must say that for the majority of parents, music is regarded as part of basic education that a child must receive similar to learning a foreign language or practicing sports. The child's own desire is not always the main factor that leads to the study of an instrument or the study of musical theory.

In France, in the standard school program, the first courses of music starts in the middle school, with children aged 10-11 years. Other children could have been in contact with music through extracurricular programs. Indeed, most musical training is done in an extra scholastic context. Some pupils attend music classes in schools managed by private associations, others follow courses with a private professor, but the majority of children who pursue musical training receive instruction in public music schools. Age is not an admission criterion in these schools. Even if musical introductory courses are proposed for children aged from 4 years old, integration in the musical formation is done at the request of the child and implies only that he/she has basic academic knowledge (elementary reading and writing). Thus, the criteria for admission are not directly related to musical ability.

These academies are organized by the Ministry of Culture. The normal course is organized in 3 multiyear cycles. To pass from one cycle to the next, children have to take exams with written tests, oral tests and musical tests. The first cycle is centred on general training (musical theory, training of a vocal or instrumental discipline). Later, pupils specialize at the entry to the second cycle and the last cycle leads them to a diploma depending on the student's future goal. The non-professional musicians can validate a certificate of end of their musical studies and those who wish to become professionals or to complete a higher formation must validate a special exam which gives access to a specialized cycle. Almost all national schools propose special courses with specific schedules, which allow some children to pursue their musical formation without their regular scholastic program being disturbed. In theory, those children are the most motivated pupils or those which wish to pursue a professional career in music, but the reality is more complex. For example, some gifted children do not have access to these structures for geographical reasons.

\section{Objectives of this research}

The main goal of the current study was to identify factors capable of explaining individual differences and heterogeneity in the development of musical talent, and in this way, to find objective criteria for better identification of children gifted in music. In this exploratory research, we sought to describe the environment of the music learner and to evaluate the importance that parents and teachers give to the main success factors for musical training. We were also interested in identifying criteria that could differentiate gifted and non-gifted children.

A part of this study has been published in the Gifted and Talented International (Pereira-Fradin \& Dubois, 2007). It is published here with the permission of the former Editor-inChief of the Gifted and Talented International, Taisir Subhi Yamin.

\section{Participants}

The first step was to ask professors of music to evaluate the potential of their pupils. The "Talented" group was 
composed with parents of 42 pupils considered as promising by their teacher, having good evaluations or having won musical awards. The "Control" group consisted of 42 parents (one parent of each pupil) of pupils for whom no particular musical potential had been detected by their professors at this stage of their training. Children were aged from 6 to 18 years old (45 girls and 39 boys; mean age: 11.6 years old). Students in music were enrolled in various educational structures (particular lessons, private schools of music, musical academies), and studied various instruments (piano, strings, brass, percussions). We questioned also 42 music teachers having 17 years of professional experience on average. The anonymity of the participants was guaranteed.

\section{Material}

The participants had to complete a 21 -item questionnaire on various aspects of their child's environment and on demographic variables (sex of the child, age, birth order, age of the parents). In order to describe the environmental aspects concerning musical training, 17 items concerned learning music, the family, the bond between parents and the musical practice of their child, and their representation of music. The variables relating to musical training were the age at which the child began training, the type of educational structure in which the child began (music academy, private school...), the current educational structure, the frequency of work of the instrument per week apart from lessons and average duration of each session. Measurements of the family context concerned parents' musical activities, the members of the family with a musical activity and the members of the family having an artistic practice regardless of its nature. The bond between parents and musical practice of their child was evaluated by questions relating to the implication of the parents in the child's musical practice, the autonomy of the pupil for training and the relation of the parents with the professor of the instrument. Finally, we were also interested in the reasons for which the child had begun musical training, who had chosen the practised instrument, the musical activities in which the child takes part and in the representation that the child has of music.

\section{Results}

An ANOVA showed that some factors were less important than others according to respondents. Indeed, for the complete sample, the factor "Implication of the parents" was evaluated as having relatively less importance in the success of the musical training $(F(3,372)=24.68, p<.001)$ compared to the factors "Motivation of the pupil", "Work of the pupil" and "Contribution of the teacher" (cf Figure $2)$.

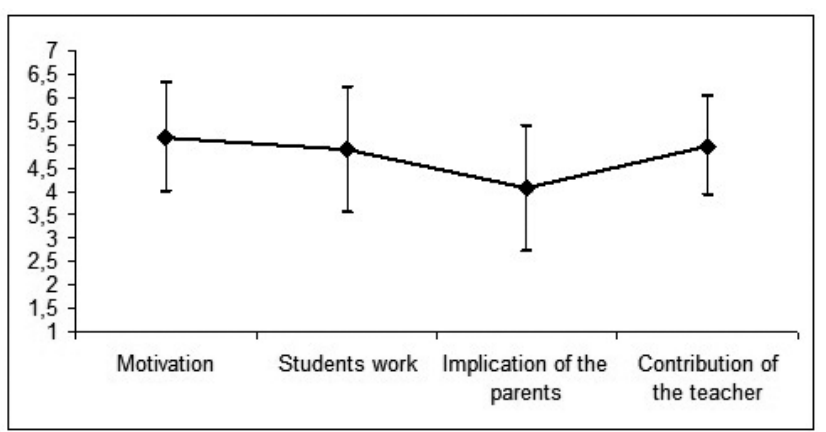

Figure 2. Average evaluations (and standard deviations of the mean) of the importance of each factor for the whole set of participants.

Moreover, we observed a significant interaction between subjects' group (parents of pupils vs. teachers) and the evaluation of the four selected factors $(F(3,372)=13.02, p<$ $.001)$. Whereas the parents gave a dominant place to the influence of the teacher on the development of the potential of the child, the teachers evaluated the work of the pupil and his or her motivation to learn as being more important (cf. Figure 3).

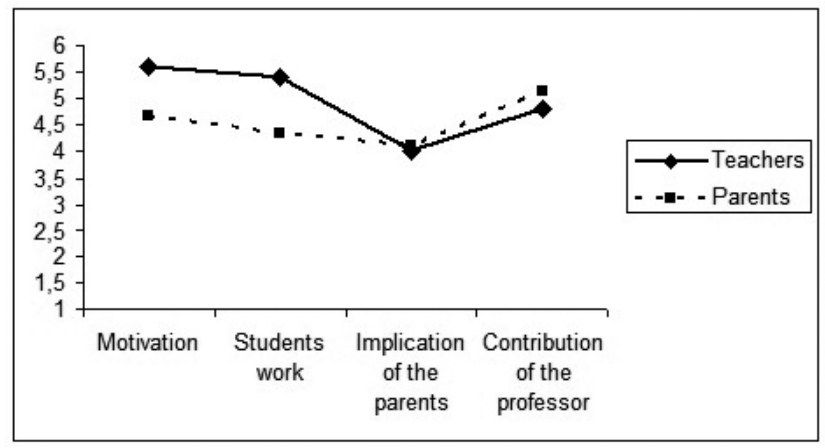

Figure 3. Effect of the statute of the participants (professor vs. parents of pupils) on the degree of importance evaluated for each factor.

No significant differences were observed between responses from parents of "Talented" children, and parents of the control group $(F(3,246)<1$; NS, cf. Figure 4).

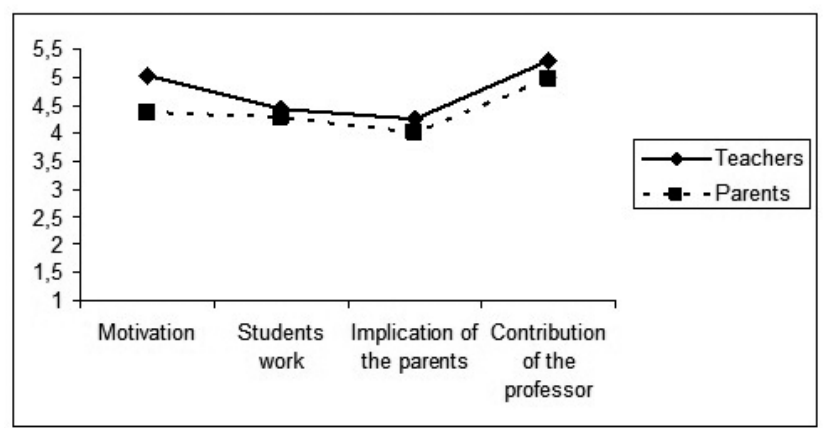

Figure 4. Evaluation of parents of "Talented" group and control group.

Finally, we examined correlations between the evaluations of the various factors by the parents and the teachers. We not- 
ed that the evaluations of the parents (all groups) were more inter correlated (cf. Table 2) that those of the teachers (cf.
Table 3). It thus seems that each factor was evaluated in a more independent way by the teachers.

Table 2. Correlations between the evaluations made by the parents of pupils.

\begin{tabular}{lcccc} 
& Motivation & Work of pupil & Implication of the parents & Contribution of teachers \\
\hline Motivation & 1 & & \\
Work of pupil & $.50 *$ & 1 & 1 & $.35 *$ \\
Implication of the parents & .11 & $.30 *$ & $.26 *$ & 1 \\
Contribution of teachers & & & \\
\hline
\end{tabular}

Legend: $* p<.05$

Table 3. Correlations between the evaluations made by the teachers.

\begin{tabular}{lccc} 
& Motivation & Work of pupil & Implication of the parents \\
\hline Motivation & 1 & & Contribution of teachers \\
Work of pupil & $.53 *$ & 1 & 1 \\
Implication of the parents & .05 & .24 & .18 \\
Contribution of teachers & .19 & .13 & 1 \\
\hline
\end{tabular}

Legend: $* p<.05$

\section{Analysis of the Multiple Correspondences}

Parents' responses to the questionnaire were scored as categorical variables. Thus, we conducted an Analysis of the Multiple Correspondences (a form of Multiway Contingency Analysis) in order to study the contingencies between these variables with the characteristics of the subjects. We sought to highlight the factors underlying our results, and in this factorial space to observe the distribution of subjects based on their characteristics.

A first analysis related to 17 questions linked with musical training based on 5 identifying characteristics (group "Talented" vs. "Control", sex, age, birth order, and age of the parents). Two axes were retained accounting for $55.7 \%$ of the variance. The questions about the age at which the child began his musical formation and the musical activities from the parents did not contribute to the construction of the factors. They were used as additional variables.

The first axe, accounting for $34.7 \%$ of explained variance, enabled us to distinguish two profiles: (1) "Obligation" profile: the child began music for only one reason, and not by his or her own will; parents chose the instrument; several people in the family practise an art (whatever it is); the parents are very involved in the training; the child does not have any autonomy; practice sessions last on average half an hour; the parents attend the lesson; for the child musical training is seen as an obligation. (2) "Passion" profile: the child began music for several reasons, and by mutual agreement between his/her entourage; the child chose the instrument; a member of his family (or none) practices an art; the parents are not involved in the training; the child is very autonomous; working sessions last more than one hour; the parents do not attend the lesson; the child conceives of music like a real passion.

The second axe accounts for $21.0 \%$ of explained variance and distinguishes two types of pupils: (1) "Leisure" profile: the child made and continues his training in a musical academy; the parents are involved in the training; the child practices less than 3 times per week his instrument apart from his lesson; in general working sessions last one hour; music is seen as a leisure activity. (2) "Obligatory activity" profile: the child made and continues training in a structure other than a musical academy; the parents are very involved; the child practices every day; working sessions last more than one hour; music training is seen as an obligatory activity.

Next we looked at the distribution of the individuals in the space defined by the selected axes. We observed that only the Group ("Talented" vs. "Control") and Age variables have a notable contribution. On axe 1, the Group factor has a contribution of $7.9 \%$ and the Age factor a contribution of $15.6 \%$ (the Age factor has also a contribution of $12.19 \%$ on axe 2). On a descriptive level, the distribution of the individuals highlighted differences in profiles according to the status of the subjects. It seems that the "Talented" pupils are more characterized by the "Passion" profile (axis 1), whereas the pupils of the "Control" group are located more on the negative side of this axis ("Obligation" profile).

Consider, for example, the case of Jeanne, 6 years old, who learned piano since one year in a musical academy. Jeanne began studying this instrument because her parents thought that it was important for the development of a child to learn how to play of a musical instrument, and she chose the piano. Jeanne comes from a family where two generations practise already an artistic activity. Her parents are very involved in all the aspects of training. Jeanne needs to be regularly pushed to practice her instrument, and her parents attend the lesson. According to statements' of her parents, Jeanne conceives music mainly as a simple leisure activity. According to teacher evaluations, Jeanne who presents an "Obligation" profile belongs to the "Control" group. On the other hand, Lucy, 15 years old, presents a "Passion" profile. Indeed, Lucy chose to learn the piano towards 8-10 years, she chose her instrument and she began her training alone even if since she follows lessons with a particular teacher. Lucy comes from a family in which only one of the grandparents practices an artistic activity. Her parents have chosen 
to not involve themselves in her training. Lucy has also a complete autonomy in her practice, and thus a complete responsibility in its progress. Besides her parents do not have any particular relation with the teacher. According to answers' given by her parents, Lucy is impassioned by music and her piano lessons. According to teacher evaluations, Lucy is a talented pupil and has already won several musical awards.

We observed that before 10 years old, pupils are closer to the "Obligation" profile on axe 1 and on the positive side of axe 2 ("Obligatory activity" profile). After 13 years old, pupils are closer to a "Passion" profile (the 11-13 years old pupils being located at an intermediate level) and on the negative side of axe 2 ("Leisure" profile). Finally, we observed a combined effect of Group and Age factors on the positioning of the individuals in the two-factor space. Whereas no differences were observed before the age of 10 years old based on musical potential evaluated by teachers, we can notice distinct profiles of the "Talented" and "Control" pupils from 11 years old. Before 10 years old all the pupils are located in an obligation process ("Obligation" profile of axis 1, "Obligatory activity" profile of axis 2). From 11 years old, one observes a progressive distinction. The "control" group tends more to be situated on the negative side of axe 1 ("Obligation" profile) whereas the "Talented" pupils are rather located on the positive side of axe 1 ("Passion" profile), but they are all, as from 11 years old, in a "Leisure" profile (negative pole of axe 2).

\section{Discussion}

The literature published on music training indicates that the factors influencing success in this field are numerous and of different types such that the probability for a child to unite all of them is rather small. It should be added that as their importance varies according to the stage of the training considered, what is positive at a given time of the training can become a limit a few years later.

The environment of the young musician, the context in which training occurs offers the possibility (or not) to develop talent. Parental involvement in a child's training is an essential factor, recognized by the literature in this field. However we observed that the child's family and musical entourage does not give a great importance to this factor in the explanation of his/her progress. Moreover, we could observe that the parents of pupils and the teachers do not agree completely on the degree of importance of factors related to the success of the musical training. Whereas for the teachers progress of pupils is primarily due to motivation and work provided, the parents regard the contribution of the teacher as the principal factor of success. This divergence of opinion could be related to a false modesty by teachers who do not wish to openly recognize teachers' influence on progress (and failure) of their pupils. In the same way, we can discuss the fact that the parents, by granting a dominating place to the role of the teacher in the success of their child, will thus implicitly decrease their share of responsibility in training. We could also highlight evaluative differences between the parents and the teachers; indeed, we observed that the evaluations of the parents, although bearing on various factors, were very dependent between them. We can believe that family can have a global vision of what would make it possible for their child to succeed. On the other hand, the evaluations of each factor made by the teachers seem to be independent. The function of the teacher comprises regular evaluation of pupils' progress. In order for this evaluation to be as objective as possible, teachers are accustomed to define precise criteria. The independence of their evaluations takes into account of their professional experience and a vision of several facets of successful training. Finally, we noted that parents of "Talented" and "Control" children evaluated the factors in the same way. The musical potential expressed by their children thus does not seem to influence knowledge and the evaluation of the factors leading the child to express this potential.

Our research made it possible to highlight profiles relating to different contexts of training, centred on the representation that the child has of music. In particular, we observed that a child considering music as an obligation has often a strong parental implication in the training and little autonomy. In contrast, the children who experience music as a passion are very autonomous and the involvement of the parents is less notable. Although parental involvement does not account for success according to respondents, it seems to have an important weight on training, as underlined by the literature. Indeed, the most gifted pupils tend to present a training context close to the highlighted "Passion" profile. However this effect is observed only after 10 years old. This suggests that children beginning their training would see this as an obligation regardless of the facilities, or early talent that they could present at this stage. The first steps in adolescence will allow a clarification of how training is considered. Only the pupils impassioned by this art will devote their energy, their time, their motivation, to succeed in this field. Autonomy and practice will make it possible for them to multiply the chances to lead to the recognition of their potential. The young musician not wishing to continue his or her training will leave this system either to continue the music in another way (learning another instrument as an autodidact for example), or move towards a different activity. Some pupils will continue with music, although no talent is recognized in them by their teacher, the desire and passion he/she will experience for this art, and a supportive environment, may lead him/her to professional success.

\section{Conclusion}

Gifted and talented children can not be considered as a homogeneous group that can easily be described. If we want to know and to understand the gifted and talented, we must focus on the inter-individual and intra-individual differences that characterize them. This can be confusing at times, be- 
cause it would be comfortable to be interested only in a single type, "representative" of all gifted and talented children. But research shows that focusing on the differences and heterogeneity is primarily a source of enrichment. Differ-

\section{References}

Alter, J. B. (1989). Creativity profile of university and conservatory music students. Creativity Research Journal, 2, 184-194.

Binet, A., \& Simon, T. (1905/1916). New methods for the diagnosis of the intellectual level of subnormals (E. S. Kite, Trans.). In The development of intelligence in children. Vineland, NJ: Publications of the Training School at Vineland.

Binet, A., \& Simon, T. (1908/1916). The development of intelligence in children (E. S. Kite, Trans.).InThe development of intelligence in children. Vineland, NJ: Publications of the Training School at Vineland.

Brasseur, S., \& Grégoire, J. (2010). L'intelligence émotionnelle-trait chez les adolescents à haut potentiel: spécificités et liens avec la réussite académique et les compétences sociales. Enfance, 1, 59-76.

Brouet, C. (2003). Les élèves en difficulté et l'échec dans les écoles de musique. Unpublished manuscript: Training Center for music teachers, RhoneAlpes, France.

Coleman, L.J., \& Cross, T.L. (2000). Socio-emotional development and the personal experience of giftedness. In Heller, K.A., Monks, F.J., Sternberg, R.J., Subotnik, R.F. (Ed.), International handbook of giftedness and talent (pp 203-2012), Elmsford, NY, US: Pergamon Press.

Courtinat, A., \& De Leonardis, M. (2010). Contextes de scolarisation, expérience scolaire et estime de soi chez des collégien (nes) à haut potentiel. Enfance, 1, 99-110.

Freeman, J. (2000). Children's talent in fine art and music - England. Roeper Review, 22, 98-101.

Gagné, F. (2000). Understanding the Complex choreography of talent development through DMGT-Based analysis. In Heller, K.A., Monks, F.J., Sternberg, R.J., Subotnik, R.F. (Ed.), International bandbook of giftedness and talent (pp 67-79), Elmsford, NY, US: Pergamon Press.

Gagné, F. (2004). Transforming gifts into talents: the DMGT as a developmental theory. High Ability Studies, 15, 119-147.

Gagne, F. (2010). Motivation within the DMGT 2.0 framework. High Ability Studies, 21(2), 81-99.

Gardner, H. (1983). Frames of mind: The theory of multiple intelligences. New York: Basic Books.

Haroutounian, J. (2000). Perspectives of musical talent: A study of identification criteria and procedures. High Ability Studies, 11(2), 137-160.

Heller, K.A. (2004). Identification of gifted and talented students. Psychology Science, 46, 302-323

.Lautrey, J. (2004). Hauts potentiels et talents : la position actuelle du problème. Psychologie Française, 49, 219-232.

Howe, M.J.A. \& Davidson, J.W. (2003). The early progress of able young musicians. In R.J. Sternberg \& E.L. Grigorenko (Eds.), The psychology of abilities, competencies and expertise (p.186-212). Cambridge : Cambridge University Press.

Lubart, T.I. \& Jouffray, C. (2006). Concepts, définitions et théories. In Lubart (ed.) «Enfants exceptionnels : précocité intellectuelle, haut potentiel et talent» (pp 12-35). Paris : Editions Bréal.

Lubart, T. I. (2006). Enfants exceptionnels: Précocité intellectuelle, haut potentiel et talent. Paris: Editions Bréal.

Manturzewska, M. (1990). A biographical study of the life-span development of professional musicians. Psychology of Music, 18, 112-139.

Marland, S.P. (1972). Education of the gifted and talented, Report to the Congress of the United States. ences measured by intelligence tests such as the WISC-IV and differences in the development of musical talent have been presented to illustrate this idea.

Pereira Da Costa, M. (2010). La place du QI dans les théories de l'intelligence appliquées aux enfants à haut potentiel. In S. Tordjman (Ed.), Aider les enfants à haut potentiel en difficulté: Repérer et comprendre, évaluer et prendre en charge (pp. 69-86). Rennes: Presses Universitaires de Rennes,

Pereira Da Costa, M., Zenasni, F. Nicolas, S. \& Lubart, T. (2013). Alfred Binet: A Creative Life in Measurement and Pedagogy. In Robinson, A. \& Jolly, J. (Eds), A century of contributions to gifted education: Illuminating Lives, New York: Routledge, Taylor and Francis. pp 23-40.

Pereira-Fradin, M. (2006). Les différences individuelles chez les enfants à haut potentiel. In Lubart (ed.) Enfants exceptionnels: précocité intellectuelle, haut potentiel et talent. (pp 36-64). Paris: Editions Bréal.

Pereira-Fradin, M., \& Dubois, A. (2007). Environmental effects on musical talent development. Gifted and Talented International, 22(2), 105-117.

Pereira-Fradin, M., Caroff, X., \& Jacquet, A-Y. (2010). Le WISC-IV permetil d'améliorer l'identification des enfants à haut potentiel?, Enfance, 1, 11-26.

Renzulli, J. S. (1986). The three-ring conception of giftedness: A developmental model for creative productivity. In R. J. Stenberg \& J. E. Davidsa (Eds), Conceptions of giftedness (pp. 53-92). Cambridge: Cambridge University Press,

Saklofske, D. H., Weiss, L. G., Raiford, S. E. \& Prifitera, A. (2006). Advanced interpretative issues with the WISC-IV, full scale IQ and general ability index scores. In L.G. Weiss et al. (eds), WISC-IV Advanced clinical interpretation (pp. 99-139). San Diego, CA: Elsevier Academic Press.

Sattler, J.M. (2001). Assessment of children: Cognitive applications (4th ed.). San Diego, CA: Author.

Silver, S.J., \& Clampit, M.K., (1990). WISC-R profiles of high ability children: interpretation of verbal-performance discrepancies. Gifted Children Quaterly, 34(2), 145-156.

Sloboda, J. A., \& Howe, M. J. A. (1991). Biographical precursors of musical excellence: An interview study. Psychology of Music, 19, 3-21.

Sosniak, L. A. (1990). The tortoise, the hare and the development of talent In M. J. A. Howe (ed.) Encouraging the development of exceptional abilities and talents. Leicester: British Psychological Society.

Sternberg, R.J., (1985). Beyond IQ: a triarchic theory of buman intelligence. Cambridge: Cambridge University Press.

Subotnik, R. F. (2000). The Juilliard model for developing young adolescent performers: An educational prototype. In C. F. M. Van Lieshout \& P. G. Heymans (Eds.), Developing talent across the life span (pp. 249-276). Philadelphia, PA: Psychology Press.

Terman, L.M. (1925). Mental and physical traits of a thousand gifted children. Standford, CA, Standford University Press.

Wechsler, D. (2005). Manuel d'administration et de cotation du WISC-IV. Paris: Editions du Centre de Psychologie Appliquée.

Weiss, L.G., Saklofske, D. H., Schwartz, D.M., Prifitera, A. \& Courville, T. (2006). Advanced clinical interpretation of WISC-IV index scores. In L.G. Weiss et al. (eds), WISC-IV Advanced clinical interpretation (pp. 140181). San Diego, CA: Elsevier Academic Press.

Winner, E., \& Martino, G. (2000). Giftedness in non-academic domains: The case of visual arts and music. In K. A. Heller, F. J. Monks, R. J. Sternberg, \& R. F. Subotnik (Eds), International bandbook of giftedness and talent (2nd ed., pp. 95-110). Elmsford, NY: Pergamon Press.

(Article received: 06-10-2015; revised: 17-09-2015; accepted:07-12-2015) 